\title{
Decomposer food web in a deciduous forest shows high share of generalist microorganisms and importance of microbial biomass recycling
}

\author{
Ruben López-Mondéjar ${ }^{1}$ - Vendula Brabcová ${ }^{1}$ Martina Štursová ${ }^{1}$ Anna Davidová ${ }^{*}$ Jan Jansa ${ }^{1}$ 'Tomaš Cajthaml ${ }^{1}$ \\ Petr Baldrian ${ }^{1}$
}

Received: 18 June 2017 / Revised: 21 January 2018 / Accepted: 27 January 2018 / Published online: 28 February 2018

(c) International Society for Microbial Ecology 2018

\begin{abstract}
Forest soils represent important terrestrial carbon $(\mathrm{C})$ pools where $\mathrm{C}$ is primarily fixed in the plant-derived biomass but it flows further through the biomass of fungi and bacteria before it is lost from the ecosystem as $\mathrm{CO}_{2}$ or immobilized in recalcitrant organic matter. Microorganisms are the main drivers of $\mathrm{C}$ flow in forests and play critical roles in the $\mathrm{C}$ balance through the decomposition of dead biomass of different origins. Here, we track the path of $\mathrm{C}$ that enters forest soil by following respiration, microbial biomass production, and $\mathrm{C}$ accumulation by individual microbial taxa in soil microcosms upon the addition of ${ }^{13} \mathrm{C}$-labeled biomass of plant, fungal, and bacterial origin. We demonstrate that both fungi and bacteria are involved in the assimilation and mineralization of $\mathrm{C}$ from the major complex sources existing in soil. Decomposer fungi are, however, better suited to utilize plant biomass compounds, whereas the ability to utilize fungal and bacterial biomass is more frequent among bacteria. Due to the ability of microorganisms to recycle microbial biomass, we suggest that the decomposer food web in forest soil displays a network structure with loops between and within individual pools. These results question the present paradigms describing food webs as hierarchical structures with unidirectional flow of $\mathrm{C}$ and assumptions about the dominance of fungi in the decomposition of complex organic matter.
\end{abstract}

\section{Introduction}

Forests are known to be vital ecosystems for maintaining the health of the planet, and their importance in the carbon (C) cycle has thus attracted special interest over the past few decades in the context of global change [1]. In addition to the services provided by these ecosystems, forests worldwide play the crucial role of $\mathrm{C}$ sinks in the terrestrial biosphere, with $\mathrm{C}$ stocks estimated at $>861 \mathrm{Pg} \mathrm{C}$ [2]. Approximately $44 \%$ of this $\mathrm{C}$ stock is stored in soil, where microorganisms

These authors contributed equally: Rubén López-Mondéjar, Vendula Brabcová.

Electronic supplementary material The online version of this article (https://doi.org/10.1038/s41396-018-0084-2) contains supplementary material, which is available to authorized users.

Petr Baldrian

baldrian@biomed.cas.cz

1 Institute of Microbiology of the CAS, Průmyslová 595, 25250 Vestec, Czech Republic are the main players in the decomposition processes and in organic matter turnover [3, 4]. As soil microorganisms have the potential to influence the feedback between climate and the global $\mathrm{C}$ cycle, a better understanding of their role in $\mathrm{C}$ fluxes in forest soils is essential if we want to model global C fluxes or predict them in the long term [5, 6].

In forest ecosystems, $\mathrm{C}$ is acquired by the activity of primary producers, trees, and other plants that fix atmospheric $\mathrm{CO}_{2}$ and supply $\mathrm{C}$ to the soil as plant root exudates, transfer $\mathrm{C}$ to symbionts such as mycorrhizal fungi, and produce dead biomass such as litter and deadwood. Due to the fact that rhizodeposited organic compounds can be readily assimilated by root symbionts and soil microorganisms, the decomposition of recalcitrant dead plant biomass has been highlighted as the primary process that results in $\mathrm{C}$ sequestration [7]. Fungi are usually considered the principal decomposers of dead plant biomass, mainly due to their filamentous nature, which allows them to colonize new substrates rapidly and to translocate nutrients such as nitrogen $(\mathrm{N})$ into this nutrient-poor pool [8]. Furthermore, many fungi produce rich batteries of extracellular enzymes that degrade recalcitrant biopolymers [9-11]. 
Although less explored than fungi, bacteria also contribute significantly to the decomposition of dead plant biomass in forest soils [1, 12]. Of genome-sequenced bacteria, $85 \%$ harbor genes that potentially attack starch or oligosaccharides, approximately $50 \%$ possess enzymes that degrade cellulose or xylan and $13 \%$ may target both [13]. However, it is unclear how this genomic potential is expressed and only few articles have touched on the question of the balance between bacteria and fungi as decomposers [14]. The combination of stable isotope probing (SIP) and phospholipid fatty acid (PLFA) analysis indicates that both bacteria and fungi receive, on a short time scale, $\mathrm{C}$ from decomposing plant litter [15] and cellulose [14]. Compared with plant biomass-derived $\mathrm{C}$, the further fate of $\mathrm{C}$ that enters the soil decomposition food web is far less understood because the fate of $\mathrm{C}$ in the biomass of fungal and bacterial decomposers has never been addressed in detail. This question is important considering that forest soils are rich in ectomycorrhizal (ECM) and saprotrophic fungi, and their biomass thus represents a large pool of organic matter with a potentially rapid turnover [16, 17]. The amount of bacterial biomass in forest soils is considered similar to that of fungi [18], and the turnover rates of bacterial cell components have been proposed to be even higher than of fungal biomass [19]. The size, potential transformation rates, and relative enrichment in phosphorus $(\mathrm{P})$ and $\mathrm{N}$ may be the reason decomposing microbial biomass should be considered a hotspot of soil activity [20, 21].

The classical concept of soil $\mathrm{C}$ flow assumes that fungi and bacteria occupy different functional niches: fungi have been proposed to be the major decomposers of recalcitrant organic matter with a K-selected strategy, whereas bacteria have been expected to be r-strategists mostly using simple compounds [6, 22]. However, this concept has now been challenged by observations of the existence of $\mathrm{r}$ - and $\mathrm{K}$ strategies in bacteria [23, 24] and the enormous phylogenetic and physiological diversity within each bacterial phylum [25, 26], as well as by the predicted and observed potential of bacteria to decompose recalcitrant organic compounds $[12,13]$. Recent studies have also shown that fungi and bacteria may overlap in substrate utilization, suggesting that $\mathrm{C}$ fluxes in soil food webs are more complex than suggested by the classical model of different substratedefined energy channels [27]. On the other hand, the level of specialization for the different compounds constituting soil organic matter of the individual decomposers within the microbial communities is also unclear. The limited information that is currently available indicates that microbial ecosystems are dominated by specialist taxa that overperform generalists in the degradation of compounds of a specific chemical composition [28].

The aim of this study was to track the flow of $\mathrm{C}$ of different origins in the microbial decomposer food web in a temperate forest soil. To do this, we have followed the respiration, biomass production, and $\mathrm{C}$ accumulation of individual microbial taxa in soil microcosms with the addition of ${ }^{13} \mathrm{C}$-labeled biomass of plant, fungal, and bacterial origin. We hypothesized that although both decomposer fungi and bacteria are able to utilize compounds of different origin, fungi are more efficient decomposers of dead biomass. In line with the observations that litter of different quality supports specific microorganisms [29] and that microorganisms decomposing fungal mycelia represent a specific part of total community [17], we hypothesized that specialist decomposers preferring different biomass of different origin, prevail. Importantly, this study should also answer questions concerning the fate of the microbial biomass $\mathrm{C}$ in forest soils.

\section{Materials and methods}

\section{Soil collection and microcosm set-up}

Soil was collected from a sessile oak (Quercus petraea) forest in the Xaverovský Háj Natural Reserve in the Czech Republic $\left(50^{\circ} 5^{\prime} 38^{\prime \prime} \mathrm{N}, 14^{\circ} 36^{\prime} 48^{\prime \prime} \mathrm{E}\right)$. The soil was an acidic cambisol with developed litter, organic, and mineral horizons. The organic soil horizon was $1.5-2.5 \mathrm{~cm}$ thick, with a $\mathrm{pH}$ of 3.7 and contained $21.5 \% \mathrm{C}$ and $0.56 \% \mathrm{~N}$ [30]. The site has previously been studied with respect to the activity of decomposition-related extracellular enzymes [30-32] and the composition and seasonal changes of the bacterial and fungal communities in soil [8, 33].

Soil was collected from the organic horizon, sieved using a 2-mm sieve, kept at $4{ }^{\circ} \mathrm{C}$ and preincubated at $10^{\circ} \mathrm{C}$ (the mean annual soil temperature) for $48 \mathrm{~h}$ before the microcosm set-up to pre-adapt. Microcosms were prepared in $100-\mathrm{ml}$ flasks containing $5 \mathrm{~g}$ of soil and $0.08 \mathrm{~g}$ of one of the six ${ }^{13} \mathrm{C}$-labeled substrates, including ${ }^{13} \mathrm{C}$-glucose (99 atom $\%{ }^{13} \mathrm{C}$; Cambridge Isotope Laboratories, MA, USA), ${ }^{13} \mathrm{C}$ cellulose from Zea mays $\left(97\right.$ atom $\left.\% \quad{ }^{13} \mathrm{C}\right),{ }^{13} \mathrm{C}$ hemicellulose from Zea mays (97 atom $\left.\%{ }^{13} \mathrm{C}\right),{ }^{13} \mathrm{C}$-plant biomass from ground maize leaves $\left(97\right.$ atom $\%{ }^{13} \mathrm{C}$; all from Isolife, Wageningen, The Netherlands), ${ }^{13} \mathrm{C}$-bacterial biomass of Streptomyces sp. PR6 and ${ }^{13} \mathrm{C}$-fungal biomass of Phanerochaete velutina PV29, which were prepared by laboratory cultivation of the microorganisms until the late stationary phase in media where ${ }^{13} \mathrm{C}$-glucose was the only $\mathrm{C}$ source. Parallel microcosms with unlabeled substrates were also prepared for each substrate, as were controls without substrate addition. Beakers with $5 \mathrm{ml}$ of $1 \mathrm{~N} \mathrm{NaOH}$ solution were placed inside each flask to capture $\mathrm{CO}_{2}$. Microcosms were slightly moistened with water to reach $60 \%$ water content and incubated at $10{ }^{\circ} \mathrm{C}$ in the dark. Three microcosms per treatment were destructively harvested after 0,7 , 
14 , and 21 days. $\mathrm{NaOH}$-containing beakers were directly processed. The microcosm materials were frozen immediately at $-80{ }^{\circ} \mathrm{C}$, freeze-dried, and stored at $-40{ }^{\circ} \mathrm{C}$.

\section{Measurement of $\mathrm{C}$ isotopic composition of $\mathrm{CO}_{2}$ and PLFA}

$\mathrm{CO}_{2}$ absorbed in the $\mathrm{NaOH}$ was quantified by titration with $0.1 \mathrm{M} \mathrm{HCl}$ using phenolphthalein $(0.5 \%)$ as a $\mathrm{pH}$ indicator. The carbonates were then precipitated with $0.5 \mathrm{M} \mathrm{SrCl}_{2}$ aqueous solution, and the $\mathrm{SrCO}_{3}$ pellets were washed three times with deionized water to completely remove $\mathrm{NaCl}$ and other soluble impurities. After washing, $\mathrm{SrCO}_{3}$ was dried at $60{ }^{\circ} \mathrm{C}$ and used for analyses of $\mathrm{C}$ isotopic composition. The

${ }^{13} \mathrm{C}$ abundance in the $\mathrm{CO}_{2}$ released from the $\mathrm{SrCO}_{3}$ samples using phosphoric acid in helium atmosphere was analyzed using a GasBench II equipped with a cold trap and coupled with a Delta V Advantage isotope mass ratio spectrometer (ThermoFischer Scientific, Waltham MA, USA).

The samples for PLFA analysis were extracted by a mixture of chloroform-methanol-phosphate buffer (1:2:0.8), according to Bligh and Dyer [34], as described

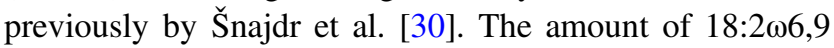
fatty acid in the samples was used as a proxy of fungal biomass (PLFAF), whereas the sum of the amounts of fatty acids i14:0, i15:0, a15:0, 16:1 $107 \mathrm{t}, 16: 1 \omega 9,16: 1 \omega 7,10 \mathrm{Me}-$ 16:0, i17:0, a17:0, cy17:0, 17:0, 10Me-17:0, 10Me-18:0, and cy19:0 served as a proxy of bacterial biomass (PLFAB). The content of all PLFA molecules (PLFAT) was used as a proxy of total microbial biomass in all treatments except the addition of plant, fungal, and bacterial biomass where PLFA were also present in the added substrate. The fungal/bacterial biomass ratio $(\mathrm{F} / \mathrm{B})$ was calculated as PLFAF/PLFAB. The ${ }^{13} \mathrm{C}$ abundance in the individual PLFAs was analyzed using a Trace 1310 gas chromatograph equipped with DB-5 column $(60 \mathrm{~m} \times 0.25 \mathrm{~mm})$, coupled to the mass spectrometer (see above) via IsoLink.

\section{DNA extraction and ${ }^{13}$ C-DNA separation}

DNA extraction and SIP fractionation were carried out from triplicate independent microcosms harvested at 7 and 21 days of incubation. DNA was extracted from $0.15 \mathrm{~g}$ aliquots of freeze-dried microcosm samples with the FastDNA Spin Kit for Soil (MP Biomedicals, Solon, $\mathrm{OH}$ ) and purified with the GeneClean Turbo Kit (MP Biomedicals, Solon, OH). Labeled DNA was separated by isopycnic centrifugation in a cesium trifluoroacetate solution (CsTFA) as previously described [14]. Briefly, three micrograms of DNA were added to the CsTFA solution with a buoyant density of $1.60 \mathrm{~g} \mathrm{ml}^{-1}$ and spun for $48 \mathrm{~h}$ at $141,400 \times$ gin $5.1 \mathrm{ml}$ tubes in L-100XP Optima Ultracentrifuge (Beckman Coulter, Brea, CA) equipped with the NVT100 rotor. After centrifugation, gradients were fractionated into 250- $\mu \mathrm{l}$ fractions. Blank controls included in each centrifugation batch with no DNA were used to determine the buoyant density of fractions. DNA in fractions was precipitated with isopropanol at $-20{ }^{\circ} \mathrm{C}$ overnight and centrifuged. Pellets were washed twice with isopropanol, vacuum-dried and resuspended in EB elution buffer (Qiagen, Valencia, CA).

Quantitative PCR was used to estimate the abundance of ${ }^{13} \mathrm{C}$ - and ${ }^{12} \mathrm{C}$-DNA in fractions with bacterial and fungal universal primers as previously described [14]. The labeled and unlabeled fractions were determined by comparing the normalized DNA concentration in fractions against fractions of unlabeled controls and avoiding the overlapping fractions; fractions representing the ${ }^{13} \mathrm{C}$-DNA and the ${ }^{12} \mathrm{C}$ DNA were separately pooled for each microcosm. The data about determination, selection, and pooling of the ${ }^{13} \mathrm{C}$ - and ${ }^{12} \mathrm{C}$-fractions from the different samples are presented in the Supplementary File S1.

\section{Microbial community analysis and statistics}

For microbial community analysis, PCR amplification of the fungal ITS2 region was performed using barcoded primers gITS7 and ITS4 [35] and of the bacterial 16S ribosomal RNA (rRNA) gene using barcoded primers 515F and 806R [36] in three PCR reactions per sample, each as described previously [37]. PCR amplicons were purified, pooled by samples, and sequenced on an Illumina MiSeq.

The amplicon sequencing data were processed using the pipeline SEED 1.2.1 [38] as described in Žif̌ćková et al. [37]. Briefly, pair-end reads were merged and whole amplicons of bacterial 16S rRNA gene or the ITS2 regions of fungal amplicons were cleaned from chimeras and clustered into operational taxonomic units (OTUs) at a $97 \%$ similarity level. Consensus sequences were constructed for each OTU, and the closest hits at a genus or species level were identified using BLASTn against the RDP [39] for bacteria or UNITE [40] for fungi. Nonbacterial and nonfungal sequences were discarded. Sequence data were deposited in the MG RAST public database [41], data set number mgs261719 for bacteria and mgs621722 for fungi. The Shannon-Wiener index, species richness, and evenness were calculated for 1250 randomly chosen sequences per sample.

Two mandatory requirements were delimited for defining an OTU as ${ }^{13} \mathrm{C}$-accumulating (i.e., ${ }^{13} \mathrm{C}$-enriched): (1) the OTU showed higher abundance in ${ }^{13} \mathrm{C}$-DNA than in ${ }^{12} \mathrm{C}$ DNA in all ${ }^{13} \mathrm{C}$-microcosms containing the same substrate; and (2) the OTU also showed higher ${ }^{13} \mathrm{C}$-DNA $/{ }^{12} \mathrm{C}$-DNA abundance ratio in all ${ }^{13} \mathrm{C}$-microcosms than in ${ }^{12} \mathrm{C}$-control microcosms containing the same substrate. The OTUs not fulfilling both conditions were considered as unlabeled.

PAST 3.03 (http://folk.uio.no/ohammer/past/) was used for statistical analysis. The Bray-Curtis dissimilarity was 
used as a metric of similarity between samples. Differences in $\mathrm{CO}_{2}$ production and PLFA content were tested using analysis of variance. Non-metric multidimensional scaling on Bray-Curtis distances was used to visualize the differences in microbial community composition, and permutational multivariate analyses of variance on Bray-Curtis distances was used to assess the significance of observed differences. Differences at $P<0.05$ were considered statistically significant.

\section{Results}

\section{Response of microbial community to substrate addition}

Microbial activity in substrate-supplemented microcosms increased significantly compared with that in unsupplemented control as reflected by higher $\mathrm{CO}_{2}$ production. $\mathrm{CO}_{2}$ production was highest after glucose, hemicellulose, and fungal biomass additions (Fig. 1a). Those substrates that induced the highest respiration also exhibited the highest ${ }^{13} \mathrm{CO}_{2}$ production (Fig. 1b) and the highest share of ${ }^{13} \mathrm{C}$ in the respired $\mathrm{CO}_{2}$ (Fig. 1c).

Total PLFA content increased in all treatments including the control. However, the only significantly higher increase of total PLFA was after the addition of hemicellulose (Fig. 1d). High incorporation of ${ }^{13} \mathrm{C}$ into microbial biomass was detected in glucose and hemicellulose treatments and was slightly lower in cellulose treatment. Higher total PLFAT increase than ${ }^{13} \mathrm{C}$-PLFAT increase relative to control, was recorded only after 14 days of hemicellulose treatment (Fig. 1e). As the ${ }^{13} \mathrm{C}-\mathrm{F} / \mathrm{B}$ ratio was higher in all treatments than in the control, fungi had incorporated more ${ }^{13} \mathrm{C}$ from glucose, cellulose, and hemicellulose into their biomass than did bacteria (Fig. 1f).

\section{Microbial communities accumulating plant and microbial C}

The microbial communities utilizing $\mathrm{C}$ from different sources were significantly different $(P<0.0001$ for both bacteria and fungi) and differed between 7 and 21 days $(P<$ 0.0001 for bacteria, $P=0.019$ for fungi; Fig. 2a). In fungi, communities accumulating ${ }^{13} \mathrm{C}$ from different sources showed a gradient along the $X$ axis, from cellulose to bacterial biomass. Moreover, fungal communities changed in time, with the exception of those on hemicellulose and glucose (Fig. 2a; Supplementary File S1). Although Ascomycota was the most abundant phylum utilizing plant biomass and its components, Mortierellomycotina dominated in the utilization of fungal and especially bacterial biomass. Bacterial communities utilizing different substrates were more similar than those of fungi based on mean Bray-Curtis similarities, especially those utilizing glucose, hemicellulose, and fungal biomass. The bacterial community associated with the decomposition of bacterial biomass was more specific. Bacterial communities degrading cellulose and plant biomass changed profoundly over time (Fig. 2a; Supplementary Fig. S2). Bacterial communities utilizing bacterial biomass were largely composed of Gammaproteobacteria (40\%) and Betaproteobacteria (40\%), whereas other substrates were richer in Bacteroidetes and Actinobacteria. Not surprisingly, the share of the slow-growing phyla Verrucomicrobia and Acidobacteria increased over time (Supplementary Fig. S2). Species richness and evenness of microbial communities were generally smaller in the ${ }^{13} \mathrm{C}$-communities than in the control, but these tended to increase over time (Supplementary Fig. S3).

\section{Microbial decomposers and the use of C-containing resources by microorganisms}

In total, 134 bacterial and 81 fungal OTUs fulfilled the requirements to be considered ${ }^{13} \mathrm{C}$-enriched (Supplementary Table S1, S2). Among them, approximately $14 \%$ of bacteria and $12 \%$ of fungi accumulated ${ }^{13} \mathrm{C}$ only from glucose. Of those microorganisms accumulating $\mathrm{C}$ from complex biomass substrates, most fungi accumulated $\mathrm{C}$ from plant biomass $(75 \%)$, fewer utilized fungal biomass $(63 \%)$, and only $36 \%$ utilized bacterial biomass. Bacteria accumulated $\mathrm{C}$ mainly from fungal biomass $(75 \%)$, fewer from plant biomass $(55 \%)$ and the least from bacterial biomass $(33 \%$; Fig. 2b). Twenty-three percent of fungal and $18 \%$ of bacterial OTUs accumulated $\mathrm{C}$ from all three complex biomass substrates (Fig. 2b). Of microbes that were able to utilize the components of plant biomass, $28 \%$ of fungi (and $28 \%$ of bacteria) accumulated $\mathrm{C}$ only from the complex plant biomass, whereas $48 \%$ of fungi (and $53 \%$ of bacteria) and $50 \%$ of fungi (and $51 \%$ of bacteria) utilized pure cellulose or hemicellulose, respectively.

OTUs that were enriched with ${ }^{13} \mathrm{C}$ belonged to $63 \mathrm{bac}-$ terial and 30 fungal genera, the majority of which were able to incorporate $\mathrm{C}$ of various origins (Fig. 3). Of the 20 most abundant bacterial genera present in the soil, 6 did not show any enrichment of ${ }^{13} \mathrm{C}$ (3 Alphaproteobacteria, 2 Actinobacteria, and 1 Acidobacteria); among 8 fungi that were not ${ }^{13}$ C-enriched, 4 were ECM taxa (Lactarius, Russula, Amanita and Tylospora). Of the enriched genera, bacteria exhibited a slightly higher proportion of those that accumulated $\mathrm{C}$ from glucose alone (14\% versus $10 \%$ of fungi). Additionally, the share of bacterial genera utilizing microbial biomass was higher: $60 \%$ were able to accumulate $\mathrm{C}$ from fungal biomass and $33 \%$ were able to accumulate $\mathrm{C}$ from bacterial biomass, compared with only $37 \%$ and $17 \%$, respectively, of fungal genera. In contrast, a large majority 

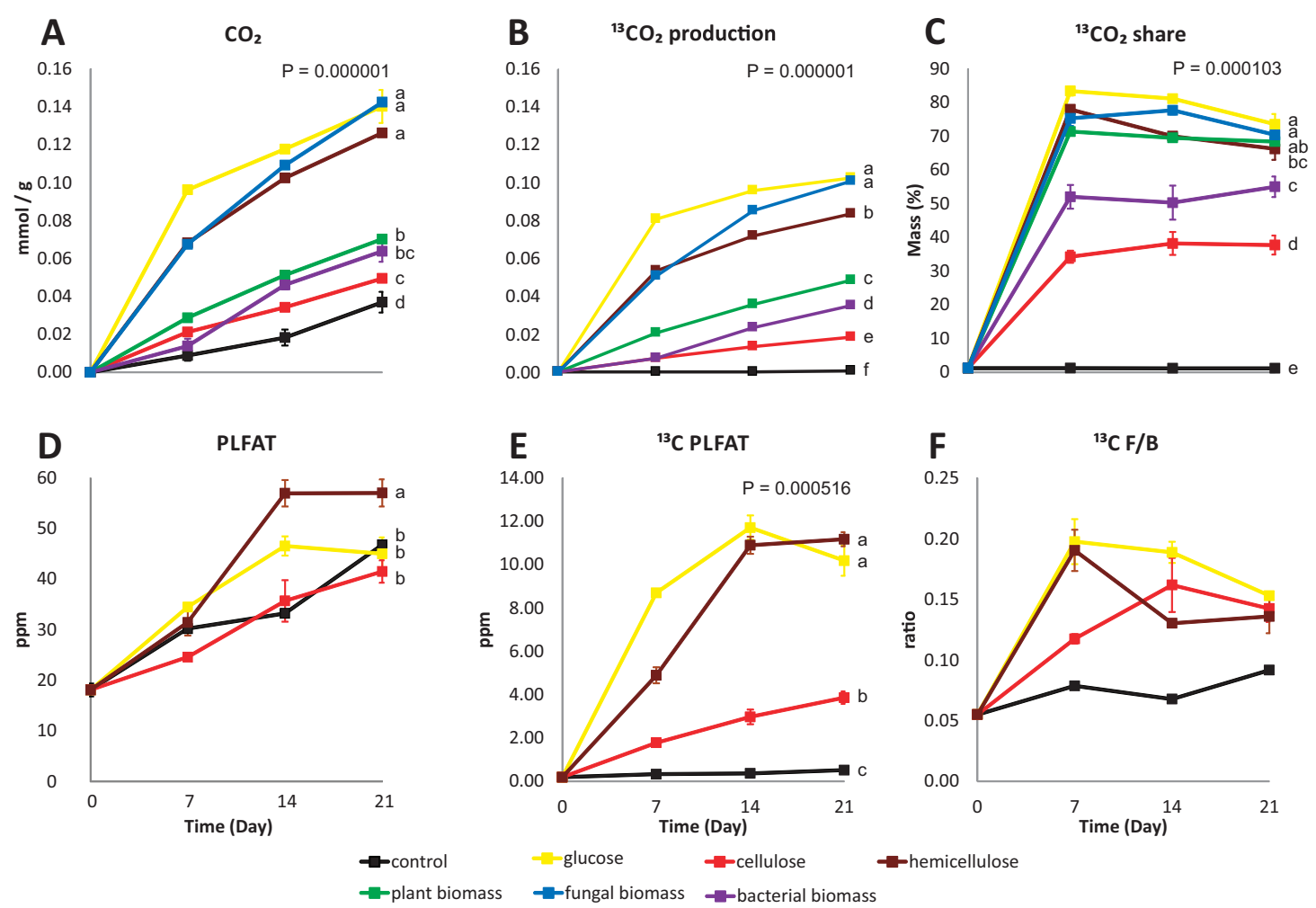

Fig. 1 Respiration and microbial biomass following the addition of plant and microbial biomass to forest soil. a Cumulative $\mathrm{CO}_{2}$ respiration and $\mathbf{b}$ cumulative ${ }^{13} \mathrm{CO}_{2}$ respiration in ${ }^{13} \mathrm{C}$-labeled microcosms; $\mathbf{c}$ the percentage of ${ }^{13} \mathrm{C}_{-} \mathrm{CO}_{2}$ in total $\mathrm{CO}_{2}$; $\mathbf{d}$ total microbial biomass (PLFAT); e total ${ }^{13} \mathrm{C}$-containing microbial biomass $\left({ }^{13} \mathrm{C}\right.$ -

of fungal genera (87\%) were able to utilize plant biomass or its components, whereas this share was only $65 \%$ for bacteria (Fig. 3). Of those taxa that became enriched in the ${ }^{13} \mathrm{C}$ community compared with the control soil, those showing the highest enrichment were typically common for multiple $\mathrm{C}$ sources. This result was the case for the bacterial genera Mucilaginibacter, Burkholderia, Herminiimonas and fungi of the genera Mortierella, Pseudogymnoascus, Umbelopsis, Cryptococcus, Astrotremella, and Trichosporon. However, in bacteria, certain taxa showed high enrichment from only one $\mathrm{C}$ source, for example, Alkanindiges on fungal biomass and Asticcacaulis on plant biomass (Fig. 3).

\section{Discussion}

Our results show that multiple fungi and bacteria were able to use all $\mathrm{C}$ sources occurring in forest soil independently of their origin and complexity. These results suggest an overlap in the substrate utilization and the absence of different energy channels for fungal and bacterial decomposers, as it has been traditionally assumed, and support the observations from agricultural soils where both bacteria and fungi were identified as primary consumers of simple, as
PLFAT); and $\mathbf{f}$ the fungal-to-bacterial PLFA ratio in the ${ }^{13} \mathrm{C}$-PLFA. The data represent the means and standard errors of three replicates. $P$ values in panels indicate the significance of differences among all treatments, and different letters at day 21 indicate pairwise significant differences between treatments

well as recalcitrant, substrates; bacteria did not show a clear preference for labile substrates [27]. In the same way, a field experiment controlling the $\mathrm{C}$ quality in forest soils also revealed no evidence in favor of the classical assumptions regarding the role of bacteria in the turnover of easily available substrates versus fungal decomposition of complex organic material [6]. It appears that there is no clear distinction between the life strategies of fungi and bacteria in soils, and their roles in these ecosystems are more similar than has been assumed thus far.

Despite the finding that both fungal and bacterial decomposers were able to degrade complex substrates in forest soil, our results indicate that fungi accumulate more $\mathrm{C}$ from plant biomass components, cellulose, hemicellulose, and glucose compared with bacteria (Fig. 1f). Importantly, our results indicate that the communities decomposing plant biomass were different from those degrading their major components (cellulose and hemicellulose; Fig. 2a), revealing the importance of other plant components (possibly less recalcitrant) as $\mathrm{C}$ or nutrient sources (Fig. 2b). Verastegui et al. [42] showed that the ${ }^{13} \mathrm{CO}_{2}$ production from labeled cellulose was substantially lower than that from simple components of plant biomass such as arabinose, xylose, and cellobiose. Here, we also confirmed the high recalcitrance 


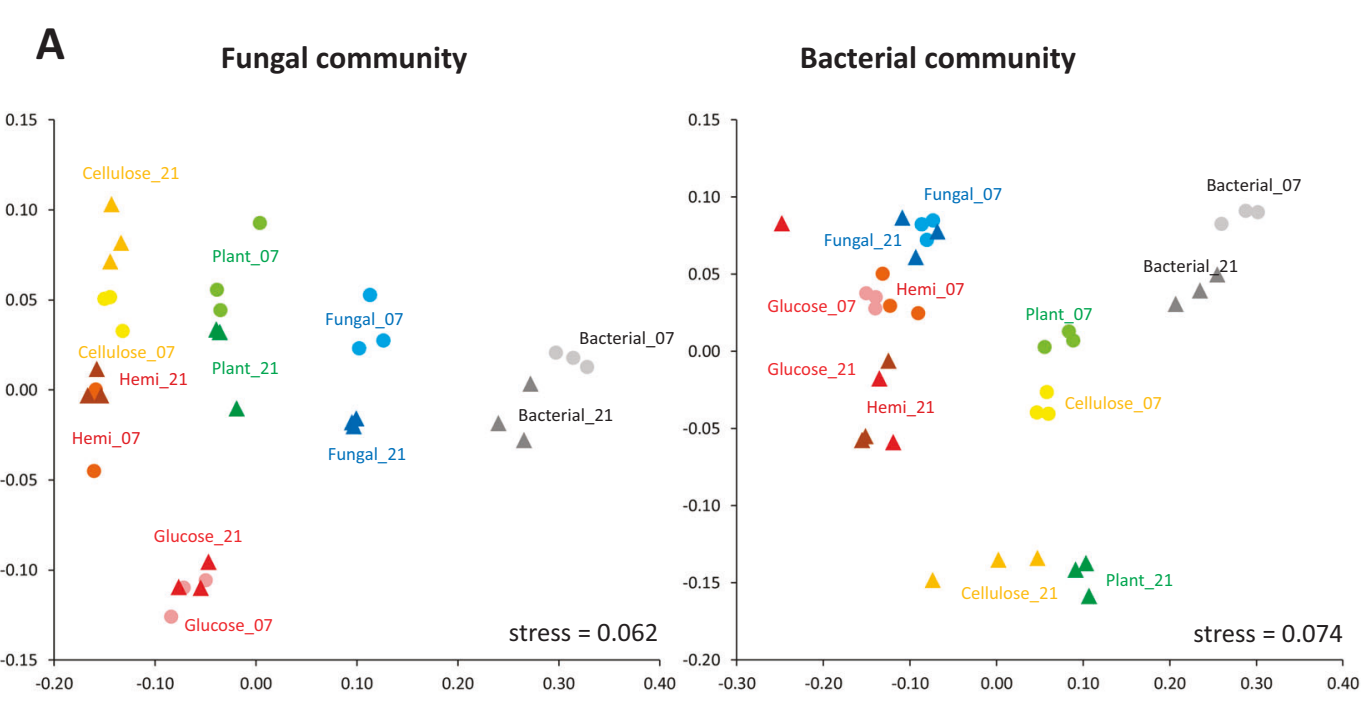

B

Fungal community

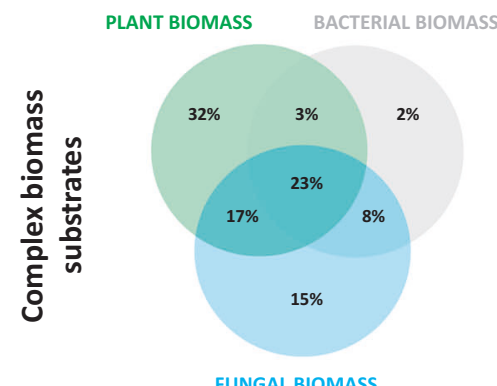

FUNGAL BIOMASS

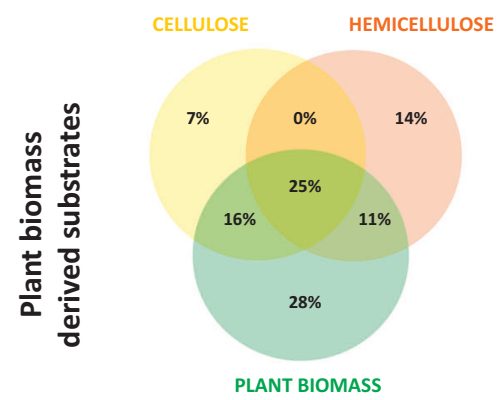

Fig. 2 a Non-metric multidimensional scaling (NMDS) analysis of soil fungal and bacterial communities accumulating carbon from different substrates; dots-day 7, triangles-21. Hemi hemicellulose. b The share of fungal and bacterial OTUs accumulating carbon from various

of cellulose to decomposition in comparison with the other substrates.

As a consequence of extracellular decomposition of biopolymers, smaller $\mathrm{C}$ compounds are not only consumed by decomposers but also released to soil, where they are available for the rest of the microbial community. The increase of labeled bacterial biomass and diversity after 21 days of incubation may be the combined result of cross-

\section{Bacterial community}

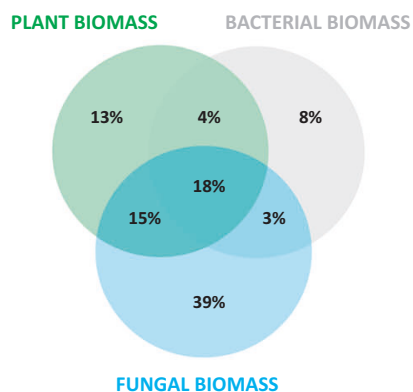

FUNGAL BIOMASS

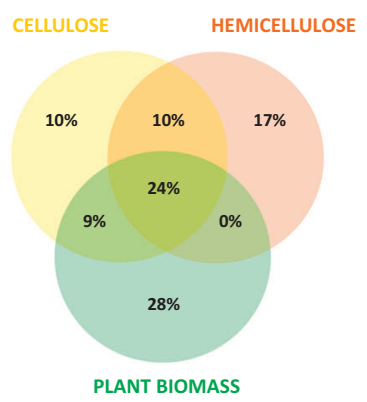

sources: The numbers represent the percentage of the total ${ }^{13} \mathrm{C}$ enriched OTUs that accumulated ${ }^{13} \mathrm{C}$ from only one, two, or three substrates

feeding of microbes on the biomass of decomposers, appearance of slow-growing taxa and the consumption of decomposition products by commensalists, sometimes termed "cheating". Bode et al. [43] showed that commensalism is of particular importance in bacteria. These authors introduced ${ }^{13} \mathrm{C}$-plant biomass in soil and used antibiotics, demonstrating that inhibition of bacteria led to preferential ${ }^{13} \mathrm{C}$ accumulation by fungi, whereas the 


\section{Bacteria}

Mucilaginibacter (Bacteroidetes) Granulicella (Acidobacteria) Actinoallomurus (Actinobacteria) Rhizomicrobium (Alphaproteobacteria) Bradyrhizobium (Alphaproteobacteria) Actinomadura (Actinobacteria) Pseudomonas (Gammanroteobacteria) Acidobacterium (Acidobacteria) Chthoniter (Verrucomicrobia) Acidipila (Acidobacteria)

Prostheco (Verraco) Candidatus Sol (Nerer (Acricrobia) Cande Cytophaga (Bacteroidetes) Cytophaga (Bacteroidetes)
Burkholderia (Betaproteobacteria) Burkholderia (Betaproteobacteri) Telmatobacter (Acidobacteria) Beijerinckia (Alphaproteobacteria) Rhodopila (Alphaproteobacteria) Acidisphaera (Alphaproteobacteria) Pedobacter (Bacteroidetes) Dyella (Gammaproteobacteria) Phenylobacterium (Alphaproteobacteria) Chitinophaga (Bacteroidetes) Aciditerrimonas (Actinobacteria) Candidatus Xiphinematobacter (Verrucomicrobia) Herminiimonas (Betaproteobacteria) Luteibacter (Gammaproteobacteria) Streptomyces (Actinobacteria) Acidisoma (Alphaproteobacteria) Ferruginibacter (Bacteroidetes) Actinospica (Actinobacteria) Frigoribacterium (Actinobacteria) Luteimonas (Gammaproteobacteria) Sphingobacterium (Bacteroidetes) Jatrophihabitans (Actinobacteria) Niastella (Bacteroidetes) Gaiella (Actinobacteria) Flexithrix (Bacteroidetes) Leptothrix (Betaproteobacteria) Devosia (Alphaproteobacteria) Acidocella (Alphaproteobacteria) Rhodocista (Alphaproteobacteria) Desulfotomaculum (Firmicutes) Sphingomonas (Alphaproteobacteria) Leifsonia (Actinobacteria) Alkanindiges (Gammaproteobacteria) Rhodopseudomonas (Alphaproteobacteria) Solirubrobacter (Actinobacteria) Rhodanobacter (Gammaproteobacteria) Hadanom (Dam Thi

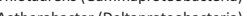
Aetherabacter (Dellaproteobacteria) Methylocystis (Alphaproteobacteria) Streptacialiphilus (Actinobacteria) Angustibacter (Actinobacteria) Herbaspirllum (Betaproteobacteria) Humibacter (Actinobacteria) Methylibium (Betaproteobacteria) Arthrobacter (Actinobacteria) Acidicaldus (Alphaproteobacteria) Mycoplasma (Tenericutes) Asticcacaulis (Alphaproteobacteria) Nakamurella (Actinobacteria) Frateuria (Gammaproteobacteria) Micromonospora (Actinobacteria) Acinetobacter (Gammaproteobacteria) Xenophilus (Betaproteobacteria) Gryllotalpicola (Actinobacteria)

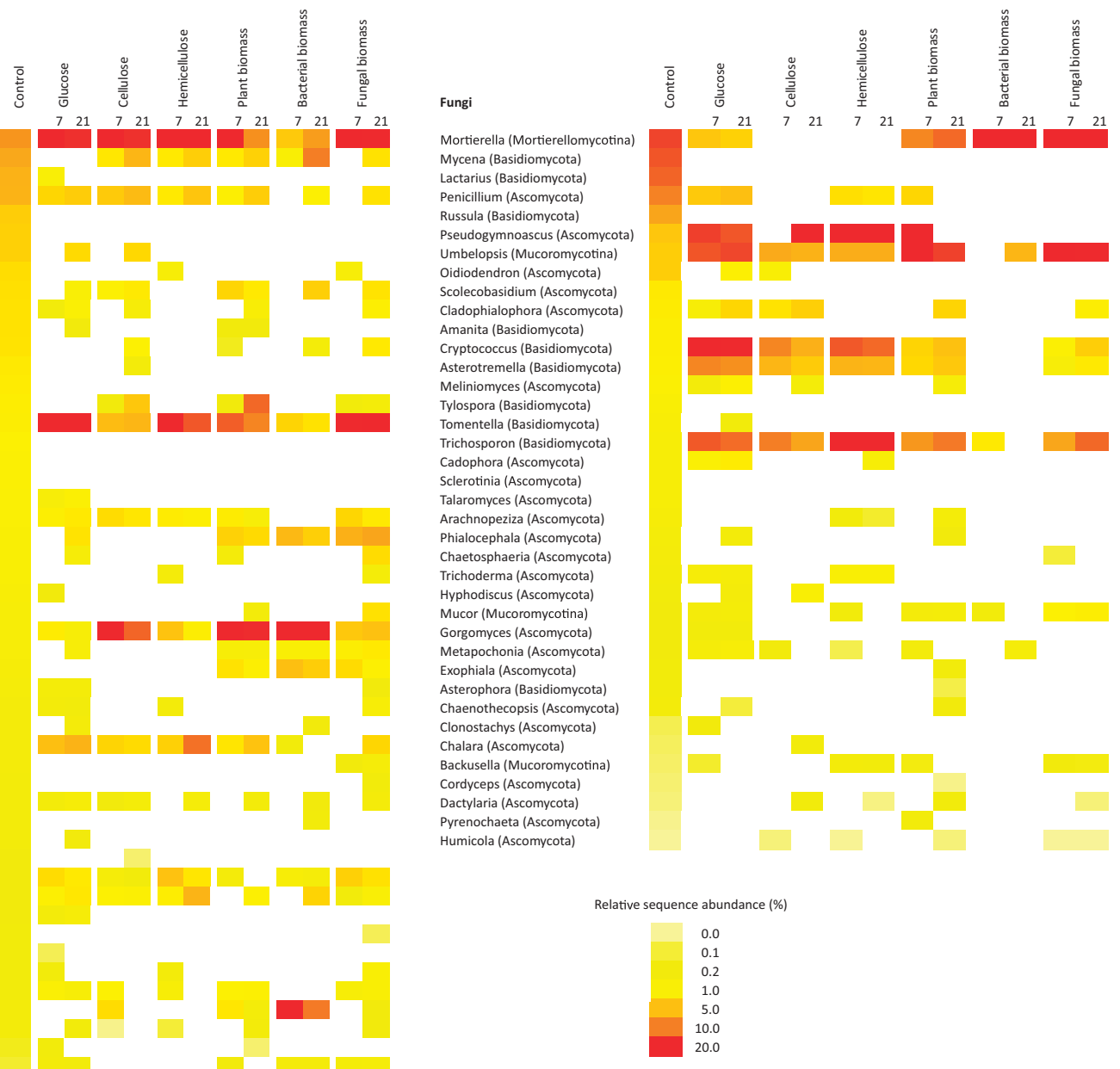

Fig. 3 Bacterial and fungal genera accumulating carbon from various sources and a comparison of their relative abundances in soil and in the different substrates. The top 20 genera of fungi and bacteria and all other significantly enriched genera are included

inhibition of fungi (and thus decomposition) resulted in reduced bacterial labeling. The flow of labeled isotopes from primary utilizers to secondary consumers is unavoidable in SIP experiments [44], and it should be clearly noted that labeling is proof of $\mathrm{C}$ accumulation, not of substrate decomposition. The bacterial taxa belonging to the phyla Acidobacteria, Actinobacteria, and Verrucomicrobia increased only after 21 days of incubation, and the dominant members of the soil communities that were not labeled after 21 days also belonged to Acidobacteria, Actinobacteria, and Alphaproteobacteria, all of which are slow growers [24]. As Acidobacteria and Actinobacteria have been shown to degrade polysaccharides of plant and fungal origin in coniferous forests [24, 45], slow or absent labeling may be caused by the slow growth of these bacteria. If this explanation holds, it would indicate that the contribution of these bacteria to the $\mathrm{C}$ flow through microbial food webs is low as a consequence of their slow growth.

Our results also confirmed the importance of fungal biomass as a $\mathrm{C}$ source in the forest soil and the important involvement of bacteria in its decomposition, as previously reported by Brabcová et al. [17]: the share of bacteria and 


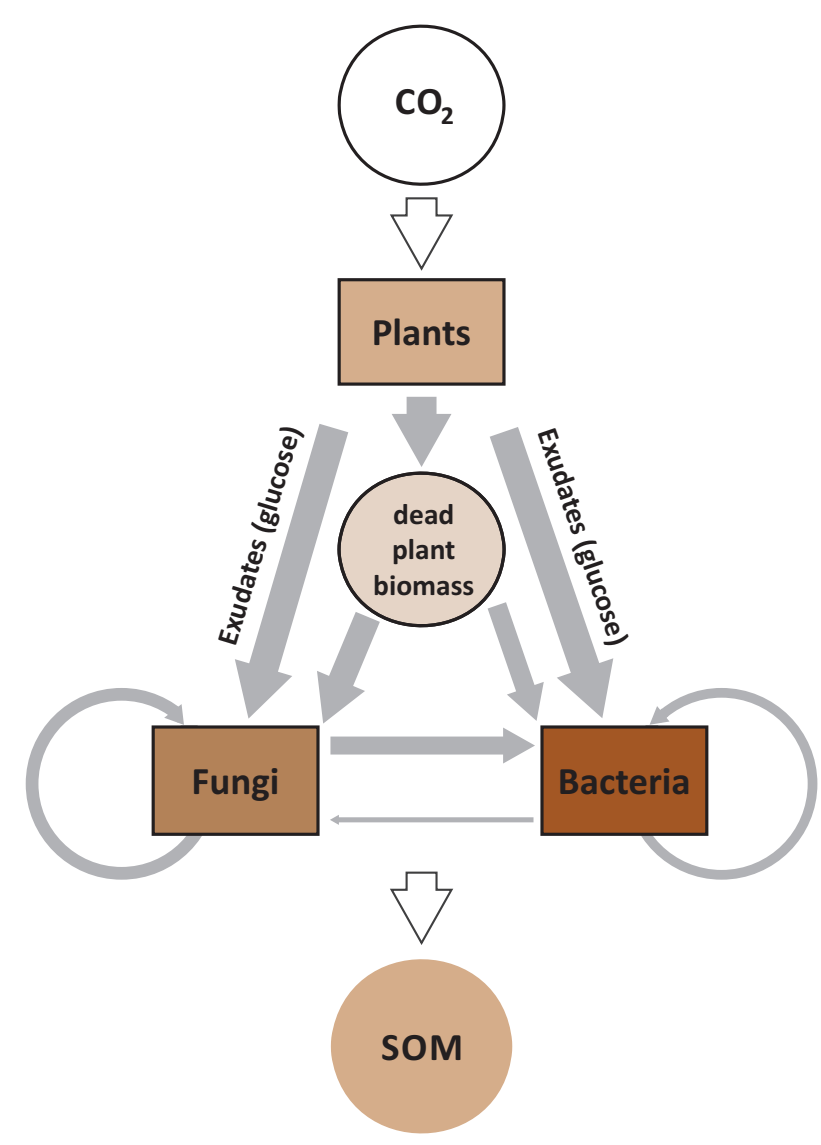

Fig. 4 Conceptual model of carbon (C) utilization preferences by saprotrophic bacteria and fungi. The arrows indicate $\mathrm{C}$ flow, and the width of the gray arrows indicates the fraction of the decomposer community that is able to utilize each compound. The brown color indicates the nitrogen concentration in each pool

fungi utilizing fungal biomass was $39 \%$ and $15 \%$, respectively (Fig. 2b). In addition to the decomposers of fungal mycelia, this group probably also contains cheaters. For example, some Planctomycetes are known to grow in association with chitinolytic microorganisms utilizing $\mathrm{N}$ acetylglucosamine [46]. Notably, some fraction of fungal biomass has been found to be highly recalcitrant [47] and is likely a major source of recalcitrant soil organic matter.

Bacterial biomass appears to be a very specific pool of $\mathrm{C}$ that is mineralized more slowly than plant and fungal biomass (Fig. 1) and that supports specific communities of fungal and bacterial decomposers (Fig. 2a). Among fungi, the genus Mortierella accounted for $>80 \%$ of the ${ }^{13} \mathrm{C}$ enriched community. The ecology of these soil molds remains poorly understood [48], but the fact that they also utilize fungal biomass and are inefficient decomposers of cellulose $[49,50]$ may indicate their importance in the recycling of microbial biomass. Bacterial communities degrading bacterial biomass were dominated by the proteobacterial genera Herminiimonas, Alkanindiges, or Acinetobacter that are widespread in naturals soils, and some of their members are known to degrade various complex substances such as hydrocarbons and aromatic compounds [51-53]. Bacterial cell walls (such as the Gram-positive strain used in our study as bacterial biomass) are rich in peptidoglycan, as well as numerous and complex glycopolymers including teichoic, teichuronic, and teichulosonic acids, glycosyl-1-phosphates and other polysaccharides [54], whose degradation may be efficiently carried out by these specific genera. The role of Proteobacteria in C sequestration and the mineralization of bacterial biomass was previously reported by Lueders et al. [55], who showed the dominance of some Gammaproteobacteria in the degradation of ${ }^{13} \mathrm{C}$-labeled Escherichia coli biomass in agricultural soils.

Fungal and bacterial decomposer communities were composed of both generalist and specialist taxa (Fig. 2). In the case of fungi, the percentage of generalists was similar to the number of specialists that utilized only one of the three biomass types (plant, fungal, or bacterial). The bacterial community exhibited a higher level of specialization, which appears to be in line with our assumption. However, the relatively high share of generalist decomposers, in addition to the fact that these generalists represented the most abundant members of enriched communities, indicates that guilds of decomposers specialized for different substrates are not as common as expected. The abundant generalist taxa of fungi often belonged to molds and basidiomycetous yeasts (Fig. 3). Basidiomycetous taxa were reported to dominate over ascomycetous yeasts in forest soils and to be able to utilize a wide spectrum of $\mathrm{C}$ sources, including cellulose, hemicellulose, and phenolics, as well as products of the enzymatic hydrolysis of lignocellulosic plant materials [56]. In forest ecosystems, the nutrient-rich nature of soil should support the existence of generalist copiotrophs exhibiting high growth rates [57]; thus, slowgrowing oligotrophs may rather be specialists that often face limitations by their nutrient source. However, our results show that generalist taxa are present among abundant and rare bacteria, rapidly growing Betaproteobacteria, and slowly growing Acidobacteria (Fig. 3). For the latter, the ability to enzymatically decompose various organic compounds was clearly proven [24, 58]; therefore, it appears that there is no link between the growth rate and the level of specialization. The absence of relationships between the growth rate, substrate utilization profile, and abundance in the soil was also recently reported for bacteria from agricultural soil [59]. Our results also indicate that it is impossible to make generalizations about the trophic strategy for high-level taxonomic groups, as the same phylogenetic group may contain both oligotrophs and copiotrophs [25]. Further studies are therefore needed to address the ecology and physiology of individual taxa, especially dominant ones $[24,60]$. 
In contrast to the classical assumption about the dominance of fungi in decomposition of complex organic matter, we demonstrated that both fungi and bacteria are involved in the assimilation and mineralization of $\mathrm{C}$ from the major complex sources existing in soil. Our results indicate that decomposer fungi are more suited to the use of plant biomass compounds, whereas more bacteria possess the ability to decompose fungal and bacterial biomass. A reason could be the contrasting demand of fungi and bacteria for $\mathrm{N}$ : bacteria that have a higher $\mathrm{N}$ content in their biomass prefer to decompose more $\mathrm{N}$-rich substrates, whereas low $\mathrm{N}$ plant biomass may be more efficiently utilized by fungi (Fig. 4). This explanation is in line with observations indicating that fungal biomass added to soil represents a hotspot of bacterial but not fungal abundance [17] and that the abundance of bacteria on decomposing plant litter begins to increase only after the initial colonization of this substrate by fungi [61]. Our results also indicate that decomposer food webs are networks with a high level of recycling of the microbial biomass pool, rather than hierarchical structures that would exist if biomass is decomposed by specialist decomposer guilds (Fig. 4). Deciphering the complex structure of the soil food web is essential for understanding the functional relevance of microbial taxa involved in the decomposition and for incorporating the microbial dynamics into $\mathrm{C}$ cycle models [6]. Furthermore, although soil microbes are the main actors in $\mathrm{C}$ cycling, their abundance and activity are affected by higher trophic levels of the soil food web [5]. In this sense, invertebrate feeding on mycelia of mycorrhizal and saprotrophic fungi has been demonstrated to influence $\mathrm{C}$ flow in the soil food web $[62,63]$ and adds to the complexity of food web structures. The incorporation of protists and soil fauna into food web models appears to be the next important step to understand both the $\mathrm{C}$ flow and, ultimately, the mechanisms controlling the sequestration of $\mathrm{C}$ by forest soil and to predict forest soil responses to future environmental conditions.

Acknowledgements This work was supported by the Czech Science Foundation (13-006763S and 18-26221Y), by the BIOCEV-Biotechnology and Biomedicine Centre of the Academy of Sciences and Charles University project no. CZ.1.05/1.1.00/02.0109 from the European Regional Development Fund in the Czech Republic, and by the Ministry of Education, Youth and Sports of the Czech Republic (LM2015055).

\section{Compliance with ethical standards}

Conflict of interest The authors declare that they have no conflict of interest.

\section{References}

1. Lladó S, López-Mondéjar R, Baldrian P. Forest soil bacteria: diversity, involvement in ecosystem processes, and response to global change. Microbiol Mol Biol Rev. 2017;81:e00063-16.
2. Pan Y, Birdsey RA, Fang J, Houghton R, Kauppi PE, Kurz WA, et al. A large and persistent carbon sink in the world's forests. Science. 2011;333:988-93.

3. Baldrian P. Forest microbiome: diversity, complexity and dynamics. FEMS Microbiol Rev. 2017;41:109-30.

4. Schimel JP, Schaeffer SM. Microbial control over carbon cycling in soil. Front Microbiol. 2012;3:348.

5. de Vries FT, Thébault E, Liiri M, Birkhofe K, Tsiafouli MA, Bjørnlund L, et al. Soil food web properties explain ecosystem services across European land use systems. Proc Natl Acad Sci USA. 2013;110:14296-301.

6. Rousk J, Frey SD. Revisiting the hypothesis that fungal-tobacterial dominance characterises turnover of soil organic matter and nutrients. Ecol Monogr. 2015;85:457-72.

7. Xia M, Talhelm AF, Pregitzer KS. Fine roots are the dominant source of recalcitrant plant litter in sugar maple-dominated northern hardwood forests. New Phytol. 2015;208:715-26.

8. Voříšková J, Brabcová V, Cajthaml T, Baldrian P. Seasonal dynamics of fungal communities in a temperate oak forest soil. New Phytol. 2014;201:269-78.

9. Eichlerová I, Homolka L, Žifčáková L, Lisá L, Dobiášová P, Baldrian P. Enzymatic systems involved in decomposition reflects the ecology and taxonomy of saprotrophic fungi. Fungal Ecol. 2015;13:10-22.

10. Sterkenburg E, Bahr A, Brandstrom Durling M, Clemmensen KE, Lindahl BD. Changes in fungal communities along a boreal forest soil fertility gradient. New Phytol. 2015;207:1145-58.

11. van der Wal A, Geydan TD, Kuyper TW, de Boer W. A thready affair: linking fungal diversity and community dynamics to terrestrial decomposition processes. FEMS Microbiol Rev. 2013;37:477-94.

12. López-Mondéjar R, Zuhlke D, Becher D, Riedel K, Baldrian P. Cellulose and hemicellulose decomposition by forest soil bacteria proceeds by the action of structurally variable enzymatic systems. Sci Rep. 2016;6:25279.

13. Berlemont R, Martiny AC. Genomic potential for polysaccharides deconstruction in bacteria. Appl Environ Microbiol. 2015;81:1513-9.

14. Štursová M, Žifčáková L, Leigh MB, Burgess R, Baldrian P. Cellulose utilization in forest litter and soil: identification of bacterial and fungal decomposers. FEMS Microbiol Ecol. 2012;80:735-46.

15. Esperschütz J, Pérez-de-Mora A, Schreiner K, Welzl G, Buegger $\mathrm{F}$, Zeyer J, et al. Microbial food web dynamics along a soil chronosequence of a glacier forefield. Biogeosciences. 2011;8:3283-94.

16. Ekblad A, Wallander H, Godbold DL, Cruz C, Johnson D, Baldrian $\mathrm{P}$, et al. The production and turnover of extramatrical mycelium of ectomycorrhizal fungi in forest soils: role in carbon cycling. Plant Soil. 2013;366:1-27.

17. Brabcová V, Nováková $\mathrm{M}$, Davidová $\mathrm{A}$, Baldrian $\mathrm{P}$. Dead fungal mycelium in forest soil represents a decomposition hotspot and a habitat for a specific microbial community. New Phytol. 2016;210:1369-81.

18. Baldrian P, Kolařík M, Štursová M, Kopecký J, Valášková V, Větrovský $\mathrm{T}$, et al. Active and total microbial communities in forest soil are largely different and highly stratified during decomposition. ISME J. 2012;6:248-58.

19. Gunina A, Dippold M, Glaser B, Kuzyakov Y. Turnover of microbial groups and cell components in soil: ${ }^{13} \mathrm{C}$ analysis of cellular biomarkers. Biogeosciences. 2017;14:271-83.

20. Wang X, Sharp CE, Jones GM, Grasby SE, Brady AL, Dunfield $\mathrm{PF}$. Stable-isotope probing identifies uncultured planctomycetes as primary degraders of a complex heteropolysaccharide in soil. Appl Environ Microbiol. 2015;81:4607-15. 
21. Brabcová V, Štursová M, Baldrian P. Nutrient content affects the turnover of fungal biomass in forest topsoil and the composition of associated microbial communities. Soil Biol Biochem. 2018;118:187-98.

22. de Boer W, Folman LB, Summerbell RC, Boddy L. Living in a fungal world: impact of fungi on soil bacterial niche development. FEMS Microbiol Rev. 2005;29:795-811.

23. Fierer N, Bradford MA, Jackson R. Toward an ecological classification of soil bacteria. Ecology. 2007;88:1354-64.

24. Lladó S, Žifčáková L, Větrovský T, Eichlerová I, Baldrian P. Functional screening of abundant bacteria from acidic forest soil indicates the metabolic potential of Acidobacteria subdivision 1 for polysaccharide decomposition. Biol Fertil Soils. 2015;52:251-60.

25. Morrissey EM, Mau RL, Schwartz E, Caporaso JG, Dijkstra P, van Gestel N, et al. Phylogenetic organization of bacterial activity. ISME J. 2016;10:2336-40.

26. Trivedi P, Anderson IC, Singh BK. Microbial modulators of soil carbon storage: integrating genomic and metabolic knowledge for global prediction. Trends Microbiol. 2013;21:641-51.

27. Kramer S, Dibbern D, Moll J, Huenninghaus M, Koller R, Krueger D, et al. Resource partitioning between bacteria, fungi, and protists in the detritusphere of an agricultural soil. Front Microbiol. 2016;7:1524.

28. Mariadassou M, Pichon S, Ebert D. Microbial ecosystems are dominated by specialist taxa. Ecol Lett. 2015;18:974-82.

29. Urbanová M, Šnajdr J, Baldrian P. Composition of fungal and bacterial communities in forest litter and soil is largely determined by dominant trees. Soil Biol Biochem. 2015;84:53-64.

30. Šnajdr J, Valášková V, Merhautová V, Herinková J, Cajthaml T, Baldrian P. Spatial variability of enzyme activities and microbial biomass in the upper layers of Quercus petraea forest soil. Soil Biol Biochem. 2008;40:2068-75.

31. Baldrian P, Merhautová V, Cajthaml T, Petránková M, Šnajdr J. Small-scale distribution of extracellular enzymes, fungal, and bacterial biomass in Quercus petraea forest topsoil. Biol Fertil Soils. 2010;46:717-26.

32. Baldrian P, Šnajdr J, Merhautová V, Dobiášová P, Cajthaml T, Valášková V. Responses of the extracellular enzyme activities in hardwood forest to soil temperature and seasonality and the potential effects of climate change. Soil Biol Biochem. 2013;56:60-68.

33. López-Mondéjar R, Voříšková J, Větrovský T, Baldrian P. The bacterial community inhabiting temperate deciduous forests is vertically stratified and undergoes seasonal dynamics. Soil Biol Biochem. 2015;87:43-50.

34. Bligh EG, Dyer WJ. A rapid method of total lipid extraction and purification. Can J Biochem Physiol. 1959;37:911-7.

35. Ihrmark K, Bodeker ITM, Cruz-Martinez K, Friberg H, Kubartova A, Schenck J, et al. New primers to amplify the fungal ITS2 region - evaluation by 454-sequencing of artificial and natural communities. FEMS Microbiol Ecol. 2012;82:666-77.

36. Caporaso JG, Lauber CL, Walters WA, Berg-Lyons D, Huntley J, Fierer N, et al. Ultra-high-throughput microbial community analysis on the Illumina HiSeq and MiSeq platforms. ISME J. 2012;6:1621-4.

37. Žifčáková L, Větrovský T, Howe A, Baldrian P. Microbial activity in forest soil reflects the changes in ecosystem properties between summer and winter. Environ Microbiol. 2016;18:288-301.

38. Větrovský T, Baldrian P. Analysis of soil fungal communities by amplicon pyrosequencing: current approaches to data analysis and the introduction of the pipeline SEED. Biol Fertil Soils. 2013;49:1027-37.

39. Cole JR, Wang Q, Fish JA, Chai BL, McGarrell DM, Sun YN, et al. Ribosomal database project: data and tools for high throughput rRNA analysis. Nucleic Acids Res. 2014;42: D633-D642.

40. Koljalg U, Nilsson RH, Abarenkov K, Tedersoo L, Taylor AFS, Bahram M, et al. Towards a unified paradigm for sequence-based identification of fungi. Mol Ecol. 2013;22:5271-7.

41. Meyer F, Paarmann D, D’Souza M, Olson R, Glass EM, Kubal M, et al. The metagenomics RAST server - a public resource for the automatic phylogenetic and functional analysis of metagenomes. BMC Bioinforma. 2008;9:386.

42. Verastegui Y, Cheng J, Engel K, Kolczynski D, Mortimer S, Lavigne $\mathrm{J}$, et al. Multisubstrate isotope labeling and metagenomic analysis of active soil bacterial communities. mBio. 2014;5: e01157-01114.

43. Bode S, Fancy R, Boeckx P. Stable isotope probing of amino sugars--a promising tool to assess microbial interactions in soils. Rapid Comm Mass Spectrom. 2013;27:1367-79.

44. Chen Y, Murrell JC. When metagenomics meets stable-isotope probing: progress and perspectives. Trends Microbiol. 2010;18:157-63.

45. Větrovský T, Steffen KT, Baldrian P. Potential of cometabolic transformation of polysaccharides and lignin in lignocellulose by soil actinobacteria. PLoS ONE. 2014;9:e89108.

46. Dedysh SN. Cultivating uncultured bacteria from northern wetlands: knowledge gained and remaining gaps. Front Microbiol. 2011;2:15.

47. Clemmensen KE, Bahr A, Ovaskainen O, Dahlberg A, Ekblad A, Wallander $\mathrm{H}$, et al. Roots and associated fungi drive long-term carbon sequestration in boreal. For Sci. 2013;339:1615-8.

48. Uehling J, Gryganskyi A, Hameed K, Tschaplinski T, Misztal PK, $\mathrm{Wu} \mathrm{S}$, et al. Comparative genomics of Mortierella elongata and its bacterial endosymbiont Mycoavidus cysteinexigens. Environ Microbiol. 2017;19:2964-83.

49. Phillips LA, Ward V, Jones MD. Ectomycorrhizal fungi contribute to soil organic matter cycling in sub-boreal forests. ISME J. 2014;8:699-713.

50. Zeng J, Zheng Y, Yu X, Yu L, Gao D, Chen S. Lignocellulosic biomass as a carbohydrate source for lipid production by Mortierella isabellina. Biores Technol. 2013;128:385-91.

51. Fuentes S, Barra B, Caporaso JG, Seeger M. From rare to dominant: a fine-tuned soil bacterial bloom during petroleum hydrocarbon bioremediation. Appl Environ Microbiol. 2015;82:888-96.

52. Kim SJ, Park SJ, Jung MY, Kim JG, Madsen EL, Rhee SK. An uncultivated nitrate-reducing member of the genus Herminiimonas degrades toluene. Appl Environ Microbiol. 2014;80:3233-43.

53. Krizova L, Maixnerova M, Sedo O, Nemec A. Acinetobacter bohemicus sp. nov. widespread in natural soil and water ecosystems in the Czech Republic. Syst Appl Microbiol. 2014;37:467-73.

54. Shashkov AS, Streshinskaya GM, Tul'skaya EM, Senchenkova SN, Baryshnikova LM, Dmitrenok AS, et al. Cell wall glycopolymers of Streptomyces albus, Streptomyces albidoflavus and Streptomyces pathocidini. Anton Leeuw. 2016;109:923-36.

55. Lueders T, Kindler R, Miltner A, Friedrich MW, Kaestner M. Identification of bacterial micropredators distinctively active in a soil microbial food web. Appl Environ Microbiol. 2006;72:5342-8.

56. Mašínová T, Bahnmann BD, Větrovský T, Tomšovský M, Merunková K, Baldrian P. Drivers of yeast community composition in the litter and soil of a temperate forest. FEMS Microbiol Ecol. 2017;93:fiw223.

57. Koch AL. Oligotrophs versus copiotrophs. BioEssays. 2001;23:657-61.

58. Lladó S, Baldrian P. Community-level physiological profiling analyses show potential to identify the copiotrophic bacteria present in soil environments. PLoS ONE. 2017;12:e0171638. 
59. Kurm V, Van der Putten WH, De Boer W, Naus-Wiezer S, Hol WHG. Low abundant soil bacteria can be metabolically versatile and fast growing. Ecology. 2017;98:555-64.

60. Pepe-Ranney C, Campbell AN, Koechli CN, Berthrong S, Buckley DH. Unearthing the ecology of soil microorganisms using a high resolution DNA-SIP approach to explore cellulose and xylose metabolism in soil. Front Microbiol. 2016;7:703.

61. Tláskal V, Voř́ršsová J, Baldrian P. Bacterial succession on decomposing leaf litter exhibits a specific occurrence pattern of cellulolytic taxa and potential decomposers of fungal mycelia. FEMS Microbiol Ecol. 2016;92:fiw177.

62. Crowther TW, Stanton DWG, Thomas SM, A'Bear AD, Hiscox J, Jones $\mathrm{TH}$, et al. Top-down control of soil fungal community composition by a globally distributed keystone consumer. Ecology. 2013;94:2518-28.

63. Johnson D, Krsek M, Wellington EMH, Stott AW, Cole L, Bardgett RD, et al. Soil invertebrates disrupt carbon flow through fungal networks. Science. 2005;309:1047-1047. 